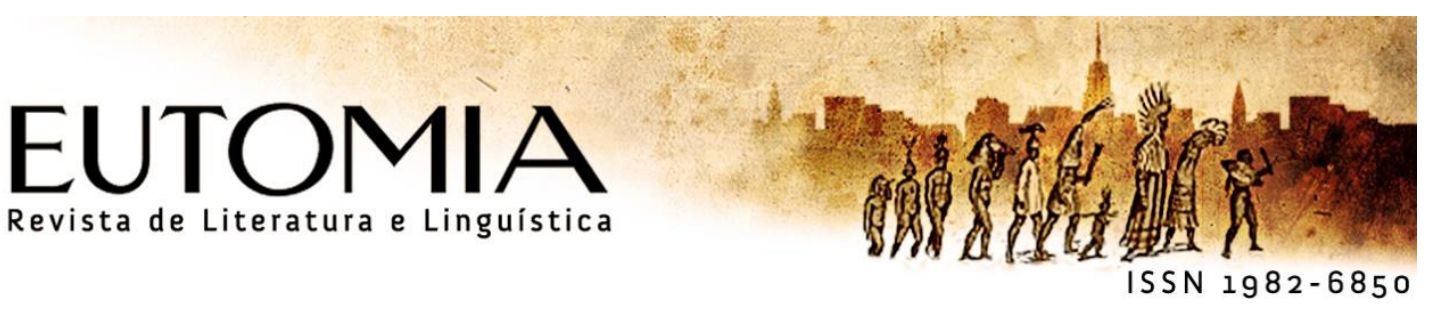

\title{
Reflexões filosóficas e personagens literárias: o comum problema do valor
}

Heloísa Helena Siqueira Correia*-UNIR

\begin{abstract}
RESUMO:
No esforço de encontrar um diálogo possível entre determinadas reflexões do filósofo Friedrich Nietzsche e narrativas de Jorge Luis Borges, objetivase tatear a configuração do problema dos valores em contexto pós morte de Deus em ambos os registros, filosófico e literário. O texto atravessa dinamicamente as fronteiras da filosofia e da literatura percorrendo caminhos de mão dupla inaugurados pela extinção do essencialismo e pelo perspectivismo, que fomenta a percepção da manipulação de valores que foram tradicionalmente atrelados ao Bem ou ao Mal. Para tanto, aborda aspectos do pensamento nietzscheano que explicitam a historicidade dos valores e a semelhança entre valores aparentemente contrários, além de identificar a inversão de valores como uma estratégia de poder. E narrativas borgeanas cujas personagens praticam ações furta-cor, a um só tempo ações infames e heroicas, o que desemboca no alerta ao leitor, no que diz respeito aos perigos éticos que o envolvem. Envolviam-no quando o leitor se balizava pelo Bem e Mal tomados como verdades absotulas e o envolvem agora, quando reconhece a transita pelo perspectivismo dos valores.
\end{abstract}

Palavras-chaves: Friedrich Nietzsche; Jorge Luis Borges; Filosofia; Literatura; Valores.

Philosophical reflections and literary characters: the common problem of moral values

\begin{abstract}
:
In an effort to find a possible dialogue between some Nietzsche's philosophical reflections and Jorge Luis Borges's narratives, this paper aims at discussing the question of moral values in a post-Death-of-God context in both authors' works - the philosophical and the literary. This text dinamically traverses the borders of Philosophy and Literature, in a twoway road that was opened by the end of essencialism and perspectivism, which fostered the perception of values manipulation of the age old Good vs. Evil. In order to achieve it, this article will apply some aspects of Nietzschean philosophy that highlight the historicity of values and the
\end{abstract}


similitude between values apparently contradictory. Also, it will identify the inversion of values as a strategy to achieve power. And Borgean narratives, where characters practice "colorful" actions, at the same time infamous and heroic. The result is a cautionary tale to the reader of the ethical dangers that he/she might get involved in. Just as the reader was manipulated by the Good vs. Evil false dichotomy, he/she has also fallen prey to the post-modern values' perspectivism.

Keywords: Friedrich Nietzsche; Jorge Luis Borges; Philosophy; Literature; Values.

O presente trabalho tateia um caminho possível entre os territórios da filosofia e da literatura para compreender como as reflexões filosóficas de Friedrich Nietzsche em torno do problema dos valores surgem encarnadas em personagens criados por Jorge Luís Borges, cujos atos concretizam no plano da ficção a crítica ao maniqueísmo e ao suposto essencialismo dos valores. Essencialismo que é autor do simulacro de determinado tipo de concepção do real em que é possível identificar seguramente as fronteiras que marcam os diferentes valores e agir a partir delas. O mencionado simulacro oblitera grosseiramente os dilemas éticos, as situações indecidíveis, a evanescência do que é signatário do Bem e do Mal, ou, ainda, a identificação das forças que se arregimentam ao lado do bom, ou as que se solidarizam com o mau, colocando-se ao seu lado.

As relações ente filosofia e literatura, aqui, são dirigidas por preocupações axiológicas que aparecem intrínsecas em alguns temas borgeanos. Portanto, tais relações partem da suposição de que há um contexto comum a ambas as obras, que diz respeito precisamente ao momento contemporâneo e posterior à morte de Deus, ao que ela significa em termos de desconstrução das certezas epistemológicas e éticas para a sociedade contemporânea. Segundo Oswaldo Giacóia Junior:

O anúncio, por Nietzsche, da morte de Deus significa o fim do modo tipicamente metafísico de pensar, na medida em que, para ele, o cristianismo, tanto como religião quanto como doutrina moral, constitui uma versão vulgarizada do platonismo, adaptada às necessidades e anseios de amplas massas populares. Por sua vez, o cristianismo constitui, para Nietzsche, a medula ética do mundo ocidental; é da seiva moral do cristianismo que se nutrem todas as esferas importantes de nossa cultura, desde a mais abstrata e rarefeita investigação das ciências formais até o plano material de organização da vida e do trabalho.

Nesse contexto de desconstrução da crença em um Deus e por consequência, de Eutomia, Recife, 24(1): 163-177, Set. 2019 
desconstrução do valor da verdade absoluta e fim da metafísica, o real se impõe como aparência e a coisa em si é aniquilada. Daí o leitor encontrar no pensamento nietzscheano o problema do valor perspectivado, condicionado, relacionado aos interesses, à força e à vontade de poder. Talvez o que haja de mais embaraçoso no comentário acima citado seja a denúncia de que inclusive as ciências formais se alimentam do cristianismo. O que choca com o ideal de objetivismo e neutralidade da ciência moderna.

Nesse sentido, a oscilação de perspectivas, movimento comum ao nos aproximarmos da questão dos valores, emerge nas narrativas borgeanas cujas personagens e narradores são portadoras, muitas vezes, de ao menos duas perspectivas no campo dos valores. O maniqueísmo implicado, por sua vez, dilui-se na oscilação, na inversão ou na equivalência dos valores. A esse respeito, são conhecidos os contos Biografia de Tadeo Isidoro Cruz, de 1949, Tema do traidor e do herói, de 1944, e La forma de la espada, também de 1944, o que será em breve tratado.

Sugere-se a existência de pontes entre a filosofia e a literatura intermitentes e que se constroem nas fronteiras descontínuas de cada disciplina. Pelas pontes, caminhos, passagens e túneis, os supostos conhecimentos específicos de cada área transitam, ente outros motivos, porque a verdade absoluta e o conhecimento objetivo não existem, o que dilui a muralha antiga postada por Aristóteles e Platão, entre a verdade e verossimilhança, e Ideias e aparências respectivamente. Novamente o estudioso Giacóia esclarece:

Para Nietzsche, a morte de Deus é uma expressão simbólica do desaparecimento desse horizonte metafísico, baseado na oposição entre aparência e realidade, verdade e falsidade, bem e mal. Isso significa que não podemos mais sustentar a crença num conhecimento objetivo, que ultrapasse a particularidade de nossos afetos.

Se o conhecimento não pode superar os afetos, doravante o que há é uma miríade de perspectivas que tornam inseguro o alicerce das ciências e da filosofia. No que diz respeito à arte, em particular a literatura, percebe-se que ela supera sua própria exigência de construção da verossimilhança e o próprio estatuto da ficção é relativizado, o que lhe possibilita a abertura para, além do campo estético, também se constituir como campo epistemológico. Critérios quanto ao que é verdade e o que é ficção, balizas relativas ao que é do âmbito do sujeito histórico e o que é posse exclusiva das personagens, e valores que 
orbitam entre moralidade e amoralidade tergiversam e transitam entre si, jogando o leitor em meio a dilemas e questionamentos.

Em se tratando da obra borgeana, é possível encontrar algumas personagens que adotam uma conduta anti-heroica, e estão no centro de ação de alguns relatos. Talvez tais personagens anti-heroicas sejam seres que respiram a atmosfera do processo de questionamento, evanescimento e morte dos valores metafísicos de nossa cultura. Jorge Luis Borges produziu contos cujas personagens infames são traidores tratados como heróis ou, ainda, personagens sobre as quais paira a indecidibilidade a respeito de seu heroísmo ou traição. É o caso de Isidoro Cruz, personagem de Biografia de Tadeo Isidoro Cruz, Kilpatrick, personagem do conto Tema do traidor e do herói, e Vincent Moon personagem narrador de La forma de la espada.

Borges parece criar personagens que oscilam entre valores opostos, de modo que o leitor se vê arruinado quanto à possibilidade de confiar definitivamente em um dos lados do valor. E exagerando a virtude do valor menos comum e menos aceito pela cultura, o texto borgeano parece querer demonstrar que o valor mais aceito e geralmente respeitado pela cultura é uma ilusão, o que não quer dizer que o valor menos aceito também não seja. $\mathrm{A}$ dúvida que passa a pairar sobre os valores lança o leitor na indecidibilidade.

A personagem presente no conto Tema do traidor e do herói (1994a. p. 496-498), de nome Fergus Kilpatrick, parece ser, a um só tempo, traidor e herói. Kilpatrick é um irlandês adorado pela Irlanda e chefe de uma conspiração que planeja uma rebelião. Vítima de um assassinato, sua memória seguiu sendo cultivada e homenageada por todos. O conto borgeano apresenta o percurso de Ryan, bisneto do heróico Kilpatrick, no levantamento de dados do herói para fins de redação de uma biografia. Tal percurso desvenda as circunstâncias da morte de Kilpatrick e, em seguida, sobre elas silencia.

A identificação de paralelismo entre fatos que envolvem Kilpatrick e os que uma vez envolveram Julio César, assim como a identificação de circunstâncias encontradas na obra de Shakespeare e na vida do herói irlandês, permitem que a investigação de Ryan caminhe em direção ao importante papel desempenhado por Nolan, o mais antigo companheiro do herói. Nolan, por ordem do próprio Kilpatrick, dedicou-se a descobrir o traidor do conclave. Para surpresa do leitor o traidor é o próprio chefe que encomendara a missão: 
Nolan ejecutó su tarea: anunció en pleno cónclave que el traidor era el mismo Kilpatrick. Demostró con pruebas irrefutables la verdad de la acusación; los conjurados condenaron a muerte a su presidente. Éste firmó su propia sentencia, pero imploró que su castigo no prejudicara a la patria (BORGES, 1994a, p. 498) ${ }^{1}$.

Por meio de um plano proposto por Nolan, a morte de Kilpatrick servirá para a emancipação da pátria. A partir desse momento, a narrativa borgeana revelará as verdadeiras circunstâncias da execução do herói e, então, percebe-se que todas as pistas anteriormente recolhidas por Ryan convergem para a sua explicação. Nas palavras de Borges:

Nolan, urgido por el tiempo, no supo íntegramente inventar las circunstancias de la múltiple ejecución; tuvo que plagiar a otro dramaturgo, al enemigo inglés William Shakespeare. Repitió escenas de Macbeth, de Julio Cesar. La pública y secreta representación comprendió varios días. EI condenado entró en Dublín, discutió, obró, rezó, reprobó, pronunció palabras patéticas y cada uno de esos actos que reflejaría la gloria, había sido prefijado por Nolan. Centenares de actores colaboraron con el protagonista; el rol de algunos fue complejo; el de otros, momentáneo. Las cosas que dijeron e hicieron perduran en los libros históricos, en la memoria apasionada de Irlanda. Kilpatrick, arrebatado por ese minucioso destino que lo redimía y que lo perdía, más de una vez enriqueció con actos y palabras improvisadas el texto de su juez. Así fue desplegándose en el tiempo el populoso drama, hasta que el 6 de agosto de 1824, en un palco de funerarias cortinas que prefiguraba el de Lincoln, un balazo anhelado entró en el pecho del traidor y del héroe, que apenas pudo articular, entre dos efusiones de brusca sangre, algunas palabras previstas (BORGES, 1994a, p. 498).

A dúvida a respeito das oposições de valores é concretizada na forjada morte do herói revelado aos companheiros como traidor, mas que, no entanto, morre como herói perante a pátria. O que leva o leitor a duvidar também do fato da traição. Se o heroísmo é desconstruído pela própria narrativa, a traição passa a ser desconstruída pelo leitor, afinal, Kilpatrick não teria agido como traidor para, justamente, fazer eclodir a rebelião que emanciparia a pátria? As aparências relativas às duas perspectivas: a que faz Kilpatrick um traidor e a que o faz herói, parecem igualmente falsas, igualmente verdadeiras e igualmente

\footnotetext{
1 "Nolan executou sua tarefa: anunciou em pleno conclave que o traidor era o próprio Kilpatrick. Demonstrou com provas irrefutáveis a verdade da acusação; os conjurados condenaram à morte seu presidente. Este assinou sua própria sentença, mas implorou que seu castigo não prejudicasse a pátria."
} 
duvidáveis. O seu desfecho é concretizado de modo a contribuir com a conspiração, e nesse sentido, sejam traição ou heroísmo, os atos de Kilpatrick trabalham para a realização de um sonho de libertação.

Essa personagem é situada agora frente a frente com uma reflexão nietzscheana que se encontra em Além do bem e do mal, texto de 1886, e trata da questão da oposição de valores nos termos que estão de acordo com a dúvida e a incerteza, fazendo o leitor adivinhar certo perigo implicado nela. Nas palavras do filósofo:

A crença fundamental dos metafísicos é a crença nas oposições de valores. Nem aos mais cuidadosos entre eles ocorreu duvidar aqui, no limiar, onde mais era necessário: mesmo quando haviam jurado para si próprios de omnibus dubitandum [de tudo duvidar]. Pois pode-se duvidar, primeiro, que existam absolutamente opostos; segundo, que as valorações e oposições de valor populares, nas quais os metafísicos imprimiram seu selo, sejam mais que avaliações-de-fachada, perspectivas provisórias, talvez inclusive vistas de um ângulo, de baixo para cima talvez, 'perspectivas de rã', para usar uma expressão familiar aos pintores (NIETZSCHE, 2005, p. 10).

Lá, onde o valor é uma tábua de salvação, a dúvida desaparece, e o elemento determinante é apenas a crença. Esta, por sua vez, não é elemento em que se possa apoiar tranqüilamente uma decisão. É preciso lembrar que, se a questão da existência dos opostos vier a ser colocada em dúvida, surge a constatação de que não estão de acordo com alguma natureza, pois que foram criadas por duas perspectivas relativas e antropomórficas. E isso sem contar o fato de que tais oposições foram privilegiadas em detrimento de todas as outras perspectivas possíveis, que poderiam ser pensadas antes do raciocínio de oposição, situadas entre os opostos, como as suas muitas nuances, ou simplesmente fora deles. Em tais avaliações, ao contrário da crença, não há nada de absoluto e definitivo. Antes, elas existem relativamente ao olhar que as inventa.

A questão da oscilação e troca dos valores apoia-se em certas semelhanças que os valores aparentemente contrários possuem, o que pode ser encontrado novamente nas reflexões de Nietzsche:

Com todo o valor que possa merecer o que é verdadeiro, veraz, desinteressado: é possível que se deva atribuir à aparência, à vontade de engano, ao egoísmo e à cobiça um valor mais alto e mais fundamental para a vida. É até mesmo possível que aquilo que constitui o valor dessas coisas boas e honradas consista exatamente no fato de serem insidiosamente

Eutomia, Recife, 24(1): 163-177, Set. 2019 
aparentadas, atadas, unidas, e talvez até essencialmente iguais, a essas coisas ruins e aparentemente opostas. Talvez! - Mas quem se mostra disposto a ocupar-se de tais perigosos 'talvezes'? Para isto será preciso esperar o advento de uma nova espécie de filósofos, que tenham gosto e pendor diversos, contrários aos daqueles que até agora existiram filósofos do perigoso 'talvez' a todo custo. - E, falando com toda a seriedade: eu vejo esses filósofos surgirem (NIETZSCHE, 2005, p. 10).

É possível dizer que os leitores de Borges esbarram com os perigosos 'talvezes'. Basta atentar para o conto até agora mencionado. A personagem Kilpatrick encarna figurativamente questões que, no campo da filosofia, são dilemas éticos que exigem reflexão demorada e trabalho constante.

Além da história de Kilpatrick, o conto intitulado La forma de la espada (BORGES, 1994a, p. 491-495), apresenta semelhante dúvida a respeito dos valores. O texto em questão abre-se como narração da personagem Borges, e em seguida modifica-se, dando lugar a um narrador-personagem que se propõe a contar, à personagem Borges, a história da cicatriz que carrega no rosto. O leitor acompanha o relato, como é de supor, com curiosidade e atenção, até que o final da narrativa Ihe golpeia a expectativa ao golpear a expectativa da personagem ouvinte. A narração abarca ações em torno de dois dos vários homens que conspiram pela independência da Irlanda. O narrador, do ponto de vista de um soldado engajado na causa e corajoso na luta, apresenta a Borges a história de um tal John Vincent Moon fraco e covarde, embora companheiro na mesma luta, e oriundo de Munster. Moon era um tipo que, segundo o narrador: "Para mostrar que le era indiferente ser un cobarde físico, magnificaba su soberbia mental"2(BORGES, 1994a, p. 494). Trata-se de um materialista dialético ofuscado pela certeza da revolução e pela autoridade que, ao invés de correr riscos, conserva-se em casa e mostra-se preocupada com a base econômica do partido. O narrador-personagem, no entanto, por uma alteração de sua rotina, surpreendente Moon em uma atitude inabitual. Leia-se:

Yo había salido cuando el amanecer estaba en el cielo; antes del mediodía volví, Moon, en la biblioteca, hablaba con alguien; el tono de la voz me hizo comprender que hablaba por teléfono. Después oí mi nombre; después que yo regresaría a las siete, después la indicación de que me arrestaran cuando yo atravesara el jardín. Mi razonable amigo estaba razonablemente vendiéndome. Le oí exigir unas garantías de seguridad personal (BORGES,

2 "Para mostrar que lhe era indiferente ser um covarde físico, magnificava sua soberba mental."

Eutomia, Recife, 24(1): 163-177, Set. 2019 
1994 a, p. 494). ${ }^{3}$

O que se segue é a referência à perseguição do delator, levada a termo pelo narrador antes que fosse preso pelos soldados, e a captura do infame traidor seguida de violência:

De una de las panoplias del general arranqué un alfanje; con esa media luna de acero rubriqué en la cara, para siempre, una media luna de sangre. Borges: a usted que es un desconocido, le he hecho esta confesión. No me duele tanto su menosprecio4 (BORGES, 1994a, p. 494).

Nesse instante desponta a revelação, mas Borges personagem e leitor ainda não a compreendem. O narrador mostra a Borges a cicatriz que leva no rosto e exclama:

- ¿ Usted no me cree? - balbuceó - ¿ No ve que llevo escrita en la cara la marca de mi infamia? Le he narrado la historia de este modo para que usted la oyera hasta el fin. Yo he denunciado al hombre que me amparó: yo soy Vincent Moon. Ahora desprécieme (BORGES, 1994a, p. 495)

A inversão de papéis do traído e do traidor responde, desse modo, às exigências do próprio ato do narrar, que poderia ser ameaçado pelo desprezo do ouvinte, caso esse já soubesse que a cicatriz é a marca da infâmia. Se o narrador estiver correto a respeito de seu ouvinte, este seria mais um tipo maniqueísta que talvez não tolerasse "ouvir" com grande entusiasmo ou interesse uma narrativa cujo protagonista não é um herói. O que Borges faz é, numa direção diametralmente oposta, sugerir a seguinte pergunta: por que insistir na primazia das histórias dos heróis e na reincidente memória de tais histórias se a história humana é igualmente planejada e realizada pelos infames, traidores e desprezíveis?

Aí se coloca novamente um daqueles perigosos 'talvezes', anteriormente mencionado por Nietzsche. O leitor precisa da inversão operada pelo narrador para não lançar mão de um suposto direito de não ler-escutar a uma história ultrajante, em nome da

\footnotetext{
3 "Eu havia saído quando o amanhecer estava no céu; antes do meio-dia voltei. Moon, na biblioteca, falava com alguém; o tom da voz fez-me compreender que falava pelo telefone. Depois ouvi meu nome; depois que eu regressaria às sete, depois a indicação de que me prendessem quando atravessasse o jardim. Meu razoável amigo estava razoavelmente vendendo-me. Ouvi-o exigir algumas garantias de segurança pessoal."

4 De uma das panóplias do general arranquei um alfanje; com essa meia-lua de aço rubriquei-lhe na cara, para sempre, uma meia-lua de sangue. Borges: a você que é um desconhecido, fiz-lhe esta confissão. Não me dói tanto seu menosprezo.

5 - Você não me acredita? - balbuciou. - Não vê que levo escrita no rosto a marca de minha infâmia? NarreiIhe a história desta forma para que você a ouvisse até o fim. Denunciei o homem que me amparou: eu sou Vincent Moon. Despreze-me agora. 
memória dos grandes homens e seus grandiosos feitos. E assim, ao final da narrativa o leitor pode se perguntar: não é o autor o verdadeiro traidor? O autor não brincou e enganou ao leitor do início ao fim? Ou será que o autor é um herói por trazer o leitor para fora do círculo vicioso do olhar que privilegia a história dos heróis?

Retornando ao pensamento do filosofo, presente ainda em Além do Bem e do Mal, pode-se denominar às ações de narrador e autor de ações furta-cor. Em suas palavras:

\begin{abstract}
Assim como no reino das estrelas são às vezes dois sóis que determinam a órbita de um planeta, e em alguns casos há sóis de cor diversa que iluminam um só planeta, ora com luz vermelha, ora com luz verde, logo irradiando simultaneamente e inundando-o de luz multicor: assim também nós, homens modernos, graças à complicada mecânica de nosso 'firmamento' somos determinados por morais diversas; nossas ações brilham alternadamente em cores distintas, raras vezes são inequívocas - e com freqüência realizamos ações furta-cor (NIETZSCHE, 2005, p. 110-11).
\end{abstract}

Ponderar sobre as assim denominadas ações furta-cor apenas explica determinados tipos de atitude no que diz respeito à corroboração de muitas perspectivas morais. A depender das ações em questão, como por exemplo a atitude do narrador borgeano e do autor, tais ações são inquietantes. Por outro lado, há outros tipos de ações, que implicam as bases de nossa vida social, como a que se pode encontrar no texto borgeano Tres versiones de Judas, de 1944, em que Judas é revelado ao leitor como Deus, e não Jesus, o suposto verdadeiro protagonista da paixão cristã (BORGES, 1994a, 514-518). O que, claramente, ameaça não apenas a história do cristianismo, mas noções do bem e do mal, tão usadas e abusadas pela moral laica, e tão caras às reflexões, ações, tratados e normatizações éticas.

Implicação semelhante identifica-se em Utopía de un hombre que esta cansado (BORGES, 1994b, p.52-56), de 1975, em que a sociedade do futuro já não têm a memória de Hitler, o esquecimento domina e nada se sabe sobre seus atos criminosos, ao contrário, o personagem histórico é tomado como filântropo. Os habitantes do futuro dão morte a si mesmos por meio de crematórios, cuja construção é atribuída à Hitler, visto, portanto, como um benfeitor, já que contribuiu para o modo de vida de tal sociedade (BORGES, 1994b, p. 52-56).

Em Deutsches Réquiem (BORGES, 1994a, p. 576-581), por sua vez, de 1949, a personagem-narrador, um diligente nazista, narra como consegue superar sua própria Eutomia, Recife, 24(1): 163-177, Set. 2019 
piedade levando à morte um célebre judeu, o pintor David Jerusalém e, a despeito da derrota alemã, considera que o empreendimento nazista é vitorioso ao substituir a "enfermedad del judaísmo, que es la fe de Jesus" (BORGES, 1994a, p. 580). A esse respeito a personagem-narrador, que se considera, assim como a cada nazista, um herói, parece ao leitor um falseador do conceito de liberdade, ao afirmar que "Lo importante es que rija la violencia, no las serviles timideces cristianas"8 (BORGES, 1994a, p. 581). E é, claro, um traidor da humanidade e um charlatão, já que, se o cristianismo levou à servidão, a violência ainda mais êxito terá em fazer o mesmo

De um outro modo, encontra-se em Biografia de Tadeo Isidoro Cruz (BORGES, 1994a, p. 561-563), de 1949, o heroísmo na figura de traidores que são desertores do exército, são eles: Martin Fierro e Tadeo Isidoro $\mathrm{Cruz}^{9}$. Tadeo é o protagonista que, após matar um homem, ser cercado e capturado pela polícia, passa a cumprir pena servindo ao exército como soldado raso até se tornar um sargento com ordem de perseguir e capturar um malfeitor que havia matado a dois homens. A história do malfeitor referida no relato borgeano entrecruza-se com a história do pai de Tadeo e com sua própria história anterior. O desfecho do conto narra ao leitor a nova tomada de posição de Tadeo quando este revê rapidamente seus antigos valores, ao mesmo tempo que combate soldados na escuridão. Nas palavras do narrador:

Comprendió que las jinetas y el uniforme ya lo estorbaban. Comprendió su intimo destino de lobo, no de perro gregario; comprendió que el otro era él.

\footnotetext{
6 "enfermidade do judaísmo que é a fé em Jesus".

7 "violência e a fé na espada".

8 "O importante é que reine a violência, não as servis timidezes cristãs".

9 No conto em questão, Borges retoma história contida no clássico da literatura argentina Martín Fierro, de José Hernández. Trata-se do episódio em que Cruz abandona sua missão oficial de prender o desertor Fierro e torna-se, ele mesmo, um desertor. Para contar a história, Borges inventa algo que não consta no clássico: a história lacunar da vida de Cruz. Esta conta com o relato de apenas alguns momentos: de quando apunhalou um homem, escondeu-se em uma mata e lutou até o amanhecer com os soldados que o prenderam, e de como se tornou um soldado e depois um sargento com a ordem de capturar o desertor Fierro. Cria-se assim um paralelismo entre a o momento em que Cruz é preso e o momento em que Cruz e seus soldados acossam Fierro para prendê-lo. Nesse instante, Cruz sente algo como uma identificação entre seu destino e o destino de Fierro, momento em que resolve desertar e lutar ao lado do "valiente". Em um outro texto borgeano, intitulado El fín, Borges ousa no trabalho de intertextualidade com o clássico argentino. No mencionado conto, o escritor argentino inventa um desenlace alternativo para a história de Fierro. Se em Martín Fierro, de José Hernández, Fierro encontra o irmão do negro que matara ao início da história e sai fracassado de um duelo verbal, em El fín, o irmão do homem assassinado por Fierro vinga-se concretamente do assassino em um duelo de facas em que Fierro é morto. Percebe-se, desse modo, que Borges contraria a escolha das letras em detrimento das armas, tal como optara Hernández. A intertextualidade entre o texto borgeano e o texto de Hernández foi ocasião de vários estudos. Acrescenta-se, ainda, que o clássico Martín Fierro também foi motivo de comentários e ensaios por parte de Borges.
}

Eutomia, Recife, 24(1): 163-177, Set. 2019 
Amanecía en la desaforada llanura; Cruz arrojó por tierra el quepís, gritó que no iba a consentir el delito de que se matara a un valiente y se puso a pelear contra los soldados, junto al desertor Martín Fierro ${ }^{10}$ (BORGES, 1994a, p. 563).

Esse é o momento de clareza a respeito do que há de nobre em um valente e a consequente tomada de posição ao lado do solitário guerreiro. E mais, o encomendado herói se redescobre tão selvagem e não-social quanto o suposto traidor. Aí a identificação inaugura um outro heroísmo e uma outra traição: o heroísmo de quem assume o que acredita ser, em detrimento dos valores gregários, e a traição ao abandonar seus próprios soldados que lhe eram fiéis e passar a lutar contra eles.

Parece novamente possível resgatar o pensamento de Nietzsche. Em Genealogia da Moral, o pensador reflete sobre a origem da má-consciência, doença que passou a infringir o homem quando ele perdeu a vida errante, a aventura e a guerra, e passou a viver delimitado pelas regras da paz social. E também quando o filósofo lembra que os castigos dados pelo Estado serviam para que esse se protegesse dos velhos instintos de liberdade, fazendo com que "[...] todos aqueles instintos do homem selvagem, livre e errante se voltassem para trás, contra o homem mesmo" (NIETZSCHE, 1998, p. 73).

O testemunho da virada do homem contra si mesmo encontra-se na vida de serviços prestados ao exército por Cruz, após ter sido preso por matar um homem, levandoo inclusive a ser um dos braços fortes das forças armadas; isto significa que se voltara contra si mesmo e contra os outros homens errantes. Ainda nas palavras de Nietzsche, presentes no mesmo texto:

A hostilidade, a crueldade, o prazer na perseguição, no assalto, na mudança, na destruição - tudo isso se voltando contra os possuidores de tais instintos: esta é a origem da má-consciência. Esse homem que, por falta de inimigos e resistência exteriores, cerrado numa opressiva estreiteza e regularidade de costumes, impacientemente lacerou, perseguiu, corroeu, espicaçou, maltratou a si mesmo, esse animal que querem 'amansar', que se fere nas barras da própria jaula, este ser carente, consumido pela nostalgia do ermo, que a si mesmo teve de converter em aventura, câmara de tortura, insegura e perigosa mata - esse tolo, esse

\footnotetext{
10 "Compreendeu que as divisas e o uniforme já o estorvavam. Compreendeu seu íntimo destino de lobo, não de cachorro gregário; compreendeu que o outro era ele. Amanhecia na imensa planície. Cruz atirou por terra o quede, gritou que não ia consentir no delito de que se matasse um valente e pôs-se a lutar contra os soldados, junto com o desertor Martín Fierro."

Eutomia, Recife, 24(1): 163-177, Set. 2019
} 
prisioneiro preso da ânsia e do desespero tornou-se o inventor da 'máconsciência'. Com ela, porém, foi introduzida a maior e mais sinistra doença, da qual até hoje não se curou a humanidade, o sofrimento do homem com o homem, consigo: como resultado de uma violenta separação do seu passado animal, como que um salto e uma queda em novas situações e condições de existência, resultado de uma declaração de guerra aos velhos instintos nos quais até então se baseava sua força, seu prazer e o temor que inspirava (NIETZSCHE, 1998, p. 73).

Cruz corresponde a esse homem que, desprovido de si mesmo, inventou a máconsciência? Parece que isso não se dá com Cruz. No caso deste, há uma retomada de seu íntimo destino, que se torna, então, mais relevante e determinador do que tudo o que vinha vivendo anteriormente às voltas com suas atribuições de soldado, marido, pai, proprietário de terras e sargento. Talvez o momento de sua lucidez seja um momento de memória primitiva que rompe os quadros sociais em que se prende a razão. Já ao início do texto, o narrador borgeano anunciava tal momento, quando afirmava a respeito de Cruz:

(Lo esperaba, secreta en el porvenir, una lúcida noche fundamental: la noche en que por fin vio su propria cara, la noche en que por fin oyó su nombre. Bien entendida, esa noche agota su historia; mejor dicho, un instante de esa noche, un acto de esa noche, porque los actos son nuestro símbolo.) Cualquier destino, por largo y complicado que sea, consta en realidad de un solo momento: el momento en que el hombre sabe para siempre quién es (BORGES, 1994a, p. 562) ${ }^{11}$.

Trata-se de um ato que não encerra a história de Cruz, mas é, emblematicamente, o seu todo significativo. Por informação do narrador, o leitor sabe que Cruz morreu de varíola negra, mas o mesmo leitor se pergunta se a personagem pôde seguir sua vida como um bravo.

E no que tange à aparente insensatez da personagem, ao passar para o lado do traidor, novamente são as palavras de Nietzsche que inspiram a compreensão de que a mudança vivida por Cruz não é um simples contrassenso, afinal, segundo o filósofo:

[...] o juízo 'bom' não provém daqueles aos quais se fez o 'bem'! Foram os

11 "(Esperava-o, secreta no futuro, uma lúcida noite fundamental: a noite em que por fim viu sua própria face, a
noite em que por fim escutou seu nome. Bem entendida, essa noite esgota sua história; ou melhor, um
instante dessa noite, um ato dessa noite, porque os atos são nosso símbolo.) Qualquer destino, por longo e
complicado que seja, consta da realidade de um único momento: o momento em que o homem sabe para
sempre quem é." Eutomia, Recife, 24(1): 163-177, Set. 2019 
'bons' mesmos, isto é, os nobres, poderosos, superiores em posição e pensamento, que sentiram e estabeleceram a si e a seus atos como bons, ou seja, de primeira ordem, em oposição a tudo o que era baixo, de pensamento baixo, e vulgar e plebeu. Desse pathos da distância é que eles tomaram para si o direito de criar valores, cunhar nomes para os valores (...) O pathos da nobreza e da distância, como já disse, o duradouro, dominante sentimento global de uma elevada estirpe senhorial, em sua relação com uma estirpe baixa, com um 'sob' - eis a origem da oposição 'bom' e 'ruim' (NIETZSCHE, 1998, p. 19).

Desse modo, Cruz é um bom que é tratado como mau, mas que recupera seu lugar original naquela lúcida noite de sua vida. E por que passara por mau por tanto tempo? Assim como também Martín Fierro? Novamente nas palavras do pensador alemão:

Perguntemo-nos quem é propriamente 'mau', no sentido da moral do ressentimento. A resposta, com todo o rigor: precisamente o 'bom' da outra moral, o nobre, o poderoso, o dominador, apenas pintado de outra cor, interpretado e visto de outro modo pelo olho de veneno do ressentimento (NIETZSCHE, 1998, p. 32).

É a moral do ressentimento que os valoriza como "maus", designação que nem sequer existe na outra moral, a dos nobres, que chega, no máximo ao valor ruim. É preciso lembrar que o pensador recupera um significado esquecido da palavra bom que, em latim, equivale a bonus que significa também guerreiro. Cruz e Fierro são guerreiros que, ao lutarem por sua nobreza, lançam ao leitor o problema que Nietzsche colocara para si mesmo, e situam-se todos, personagem, leitor e reflexão filosófica na mesma área movediça e perigosa das escolhas éticas.

A libertação do homem em relação às amarras do essencialismo, deflagrada com o acontecimento da morte de Deus narrado por Nietzsche e sobre o qual o filósofo muito refletiu, inaugura novas possibilidades de construção de conhecimento, elaboração de normas e organização social. Entretanto traz problemas que ora evitados, ora indecidíveis, criticados ou enfrentados provocam complexas relações morais e éticas nas relações sociais. A literatura de Borges parece partilhar tais problemas e o faz de modo diverso da filosofia, em âmbito ficcional e latino-americano. Mas com o tipo de agudeza de espírito que se encontra facilmente em filósofos, Borges alerta seu leitor ao exagerar situações de inversão valorativa.

Os contos Tres versiones de Judas, Utopía de un hombre que esta cansado e Eutomia, Recife, 24(1): 163-177, Set. 2019 
Deutsches Réquiem, em especial, parecem demonstrar que a relativização total dos valores é perigosa e que talvez não possamos prescindir de criar limites para o perspectivismo dos valores. Ao explicitar perspectivas que implicam o judaísmo e o nazismo, o leitor estanca no trânsito dos valores. Sim, aí também se esbaterá com o "talvez" e lhe caberá a escolha e suas implicações, ele, leitor, que não vive nunca apenas a ficção, sabe agora do perigo que que ronda a liberdade. Sabe-se leitor de Nietzsche e Borges.

\section{Referências}

BORGES, Jorge Luis. Obras completas: 1952-72. Buenos Aires: Emecé Editores, 1993. V.2, $527 p$.

. Obras completas: 1923-49. Buenos Aires: Emecé Editores, 1994a. v.1, 638p.

. La forma de la espada. In: .Obras completas: 1923-49. Buenos Aires: Emecé

Editores, 1994a. v.1, p. 491-495.

Tres versiones de Judas. In: Obras completas: 1923-49. Buenos Aires:

Emecé Editores, 1994a. v.1, p. 514-518.

. Deutsches réquiem. In: Obras completas: 1923-49. Buenos Aires: Emecé Editores, 1994a. v.1, p. 576-581.

Biografia de Tadeo Isidoro Cruz. In: Obras completas: 1923-49. Buenos Aires: Emecé Editores, 1994a. v.1, p. 561-563.

Tema del traidor y del héroe. In: . Obras completas: 1923-49. Buenos Aires:

Emecé Editores, 1994a. v.1, p. 496-498.

Obras completas: 1975-85. Buenos Aires: Emecé Editores, 1994b. v.3, 518p.

Utopia de um hombre que esta cansado. In: Obras completas: $1975-85$. Buenos Aires: Emecé Editores, 1994b. v.3, p. 52-56.

GIACÓIA JUNIOR, Oswaldo. Nietzsche. São Paulo: Publifolha, 2000. 92p. (Folha explica)

NIETZSCHE, Friedrich. Genealogia da moral: uma polêmica. Tradução de Paulo César de Souza. São Paulo: Companhia das Letras, 1998. 168p.

Além do bem e do mal: prelúdio a uma filosofia do futuro. Tradução, notas e posfácio de Paulo César de Souza. São Paulo: Companhia das letras, 2005. 
* Doutora em Teoria e História Literária pela UNICAMP. Professora do Mestrado em Estudos Literários e do Programa de Pós-Graduação em Filosofia- UNIR. É membro do GT da ANPOLL "Vertentes do insólito ficcional". Desenvolve pesquisa sobre as relações entre literatura e filosofia, o insólito literário em textos de literatura brasileira e latino-americana, e desenvolve projeto no campo dos Estudos Animais e da Ecocrítica. 